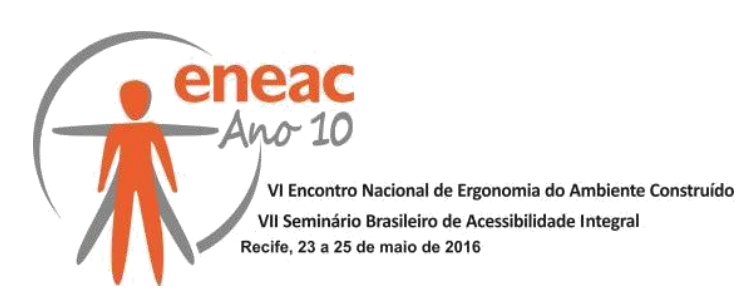

\title{
A QUALIDADE ESPACIAL DO PROGRAMA DE HABITAÇÃO SOCIAL VILA DIGNIDADE DE PRESIDENTE PRUDENTE (SP)
}

\author{
YOSHIDA, Débora M. (1); \\ FONTES, Mariana F. (2); \\ SILVA, Renata B. A. (3); \\ FARIA, Obede Borges (4); \\ FONTES, Maria Solange Gurgel de Castro (5); \\ MAGAGNIN, Renata Cardoso (6) \\ (1) Universidade Estadual Paulista "Julio de Mesquita Filho" - UNESP, Mestranda \\ e-mail:debora yoshida1@hotmail.com \\ (2) Centro Universitário de Araraquara, Graduação \\ e-mail:arq.marianafigueiredo@hotmail.com \\ (3) Universidade do Oeste Paulista, Graduação \\ e-mail:renataaguilar@hotmail.com \\ (4) Universidade Estadual Paulista "Julio de Mesquita Filho" - UNESP; Doutor \\ e-mail: obede.faria@gmail.com \\ (5) Universidade Estadual Paulista "Julio de Mesquita Filho" - UNESP; Doutora \\ e-mail: sgfontes@faac.unesp.br \\ (6) Universidade Estadual Paulista "Julio de Mesquita Filho" - UNESP; Doutora \\ e-mail: magagnin@faac.unesp.br
}

\begin{abstract}
RESUMO
Com o grande contingente de idosos, atualmente se incorporando na sociedade, também vem crescendo o número de habitações residenciais para atender esta parcela da população. Dentre os programas de habitação subsidiados pelo governo, este artigo tem por objetivo analisar a qualidade espacial do Programa de habitação social Vila Dignidade implantado na cidade de Presidente Prudente (SP). A metodologia utilizada foi composta por: análise do deslocamento linear, utilização dos ambientes e entrevistas estruturadas. Os resultados mostraram que embora as residências tenham sido projetadas de acordo com os princípios do desenho universal os ambientes não permitem o deslocamento linear de um usuário de cadeira de rodas. O diagnóstico pode servir de referência para proposição de diretrizes e identificação de problemas em outros programas, além de ser referência para que os novos projetos sejam mais inclusivos.
\end{abstract}

Palavras-chave: Idosos; Mobilidade Reduzida; Acessibilidade espacial. 


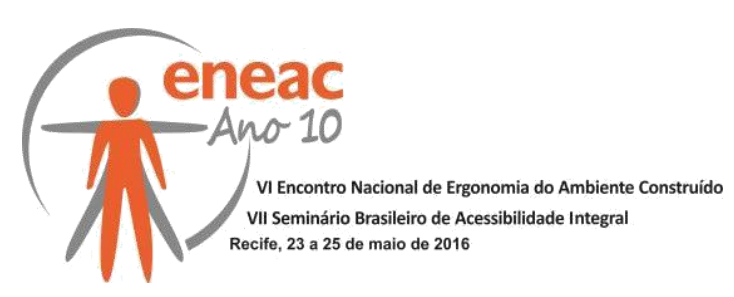

\begin{abstract}
With the large number of elderly people that society has incorporated residential dwellings were created to serve them. Among the housing programs subsidized by the government, this article aims to analyze the spatial quality of the social housing program Vila Dignity deployed in the city of Presidente Prudente (SP). The methodology consisted of: the linear displacement analysis and use of environments, structured interview. The results showed that although the homes have been designed according to the principles of universal design environments do not allow the linear displacement of a wheelchair user. The diagnosis can serve as reference for proposing guidelines and identifying problems in other programs; besides being a reference for new projects to be more inclusive.
\end{abstract}

Keywords: Elderly; Reduced mobility; Spatial accessibility.

\title{
1 INTRODUÇÃO
}

O Brasil nos últimos 20 anos está passando por uma transição demográfica decorrente do envelhecimento da população, do aumento da expectativa de vida e da diminuição da taxa de natalidade, dados confirmados nos últimos dois censos brasileiros. Em 1990 a expectativa de vida era de 66,9 anos, em 2000, passou para 70,4 anos, e em 2010, era de 73,1 anos - 10,2\% da população. Estima-se que em 2050 esta faixa etária poderá chegar a 81,3 anos o que representará $29,7 \%$ da população (IBGE, 2015).

A Organização Mundial de Saúde (OMS) confirma estas projeções do IBGE. De acordo com a OMS até 2025, o Brasil será o sexto país do mundo em número de idosos (pessoas com 60 anos ou mais de idade), portanto, é necessário que haja políticas públicas voltadas a esta faixa etária que garantam uma maior qualidade de vida a esta parcela da população.

No Brasil, a maioria dos municípios dispõe de programas voltados para os idosos nas áreas de combate à violência, melhoria da acessibilidade nos ambientes públicos e de transportes, capacitação de cuidadores, dentre outros programas; no entanto, há carência de políticas públicas em relação à habitação para a terceira idade.

Dados da Secretaria Nacional de Habitação disponibilizados em 2008 mostraram que o déficit habitacional no Brasil era de aproximadamente 5.546 milhões de domicílios. No entanto, não há dados específicos em relação à demanda por habitação voltada aos idosos.

Apesar do esforço do Governo Federal em reduzir o déficit habitacional do país, os Programas Habitacionais para a população idosa são escassos, pois demandam verba e disponibilidade de recursos não só construtivos, como também na área da saúde, assistência social dentre outras áreas (SCHUSSEL, 2012).

Para atender a esta demanda crescente o país implantou alguns tipos de moradias voltadas aos idosos, chamadas de residências seniores e foram criadas a partir de políticas públicas e cuja maioria foi subsidiada pelo governo. Os tipos de acomodação encontradas são: Moradia Assistida, Moradia Independente, Moradia Congregada, Comunidade de Cuidado Contínuo a Aposentados, Clínicas, Clínicas especializadas em Mal de Alzheimer, entre outros programas (BESTETTI, 2006).

Há uma tendência mundial na diminuição da população idosa morando com os filhos, pois as pesquisas evidenciam que uma parcela significativa de idosos morando sozinho. Este fenômeno é conhecido como famílias unipessoais (MONTEIRO, 2012). Esta tendência é decorrente do aumento da qualidade de vida e o prolongamento da longevidade. No entanto, ainda é comum os idosos serem cuidados por familiares ou em locais especializados que possuem cuidados especiais direcionados a essa faixa etária.

Um dos problemas enfrentados por estas famílias unipessoais é a própria limitação física do idoso, pois o processo de envelhecimento se caracteriza por uma mudança cognitiva, na 


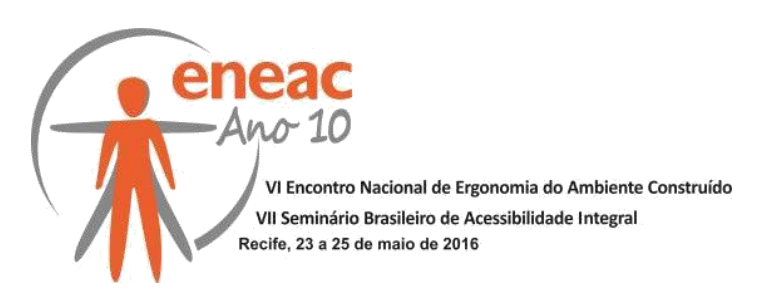

audição, na visão, na postura do indivíduo. Estes fatores predispõem o idoso a algumas doenças e quedas, que podem estar associadas não só por fatores físicos, como também por obstáculos ambientais ou arquitetônicos como, por exemplo, pisos escorregadios, falta de iluminação adequada, tapetes, escadas ou rampas sem corrimão (HAZIN, 2012).

$O$ processo de envelhecimento pode gerar diferentes necessidades espaciais para os idosos, e este processo deve ser compreendido e estudado a fim de se projetar espaços acessíveis, proporcionando ambientes livres de acidentes e quedas (BINS ELY; DORNELES, 2006). A presença de obstáculos, barreiras arquitetônicas, a falta de acessibilidade espacial e o mau planejamento do projeto arquitetônico tornam os idosos mais propensos a ter problemas na utilização dos ambientes (MONTEIRO, 2012; SÂMIA, 2008).

Qualquer atitude de risco por parte dos Idosos pode causar acidentes e quedas dentro do ambiente doméstico. Os idosos independentes tendem a se acidentarem mais (riscos de quedas) do que aqueles idosos dependentes, por apresentarem pessoas auxiliando em suas tarefas diárias. Portanto, a adequação do ambiente e do mobiliário são agentes facilitadores da mobilidade dentro do espaço residencial (MILANI, 2014).

A adaptação do ambiente doméstico, a adequação e organização espacial, fazem com que os riscos de quedas e a dificuldade motora sejam reduzidos, garantem ao idoso independentemente da sua condição física ou limitação independência de movimento e deslocamento dentro de seu próprio ambiente (SÂMIA, 2008).

De acordo com Bestetti (2006), em função das modificações físicas decorrentes do próprio envelhecimento, o projeto habitacional destinado aos idosos deve levar em consideração os seguintes aspectos espaciais: acessos (proporcionar visibilidade e distância); circulação (tipo e tamanho); dimensões (ambientes e equipamentos); eliminar barreiras arquitetônicas (escadas, desníveis, sistema de segurança); melhorar as condições ambientais (iluminação, ventilação e calefação, acústica); revestimento (textura, temperatura e padronagem); condições de manutenção (facilidade na limpeza, adequação e acessibilidade); aspectos psicodinâmicos (cor, linha e tamanho); aspectos tecnológicos (sistema de comunicação, segurança contra incêndio e controle de insolação) e outros aspectos (campainhas de alerta visual, adequação das instalações para computadores e luminária de emergência).

Para se projetar um ambiente que supra as necessidades físicas dos idosos, o mesmo deve estar livre de obstáculos, ser de fácil manutenção, estar bem iluminado e bem sinalizado, evitando assim acidentes e quedas. Ademais, deve ser atrativo para todos os idosos e estar de acordo com as características biomecânicas e antropométricas da população usuária, ou seja, área de alcance dos equipamentos, uso de cores diferentes para facilitar a compreensão e assimilação, paredes e pisos coerentes, mobiliários, formas e volumes (BINS ELY, DORNELES, 2006).

Diante dessa realidade, este artigo tem por objetivo apresentar a análise da qualidade espacial de residências do Programa Habitacional Social Vila Dignidade, localizado no município de Presidente Prudente (SP), cujos moradores são idosos com mobilidade reduzida.

\section{Metodologia}

\subsection{Objeto de estudo}

O Programa Vila Dignidade é uma parceria entre as Secretarias Estaduais de Habitação, Cultura, Economia e Planejamento, Assistência e Desenvolvimento Social, Companhia de Desenvolvimento Habitacional e Urbano (CDHU), Fundo de Solidariedade e 


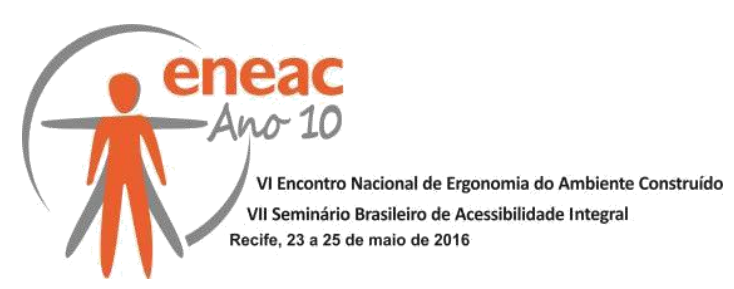

Desenvolvimento Social e Cultural (FUSSESP) e Prefeituras Municipais. Este programa visa oferecer à população idosa, moradia apropriada a esta faixa etária, oferecendo garantia em sua independência e segurança, propiciando um aumento na qualidade de vida desta população, além de diminuir a taxa de pessoas que vivem em asilos (asilamento).

De acordo com a CDHU, no ano de 2010, já existiam convênios firmados em nove cidades do Estado de São Paulo: Araraquara com 20 unidades, Caraguatatuba com 20 unidades, Itapetininga com 16 unidades, Itapeva com 18 unidades, Ituverava com 24 unidades, Limeira com 22 unidades, Presidente Prudente com 24 unidades, Ribeirão Preto com 18 unidades e São José do Rio Preto com 14 unidades.

Para participar da seleção para moradia na Vila Dignidade, a pessoa deve ter faixa etária acima de 60 anos, ser residente no município há pelo menos dois anos, ser solteiro, viúvo, casado, sem vínculo familiar sólido, com renda familiar de até dois salários mínimos e que sejam independentes para realização das tarefas diárias.

O estudo de caso foi realizado no município de Presidente Prudente (SP), cidade de médio porte localizada na região Oeste do Estado de São Paulo. A Vila Dignidade dessa cidade está localizada na região norte do município. O conjunto é composto por 24 unidades habitacionais térreas, possui uma academia ao ar livre e um salão multiuso, ambos localizados na área central do terreno. O terreno do condomínio é em aclive, possuindo uma área de $4.547,72 \mathrm{~m}^{2}$ (Figura 1).

\section{Figura 1 - Implantação da Vila Dignidade}

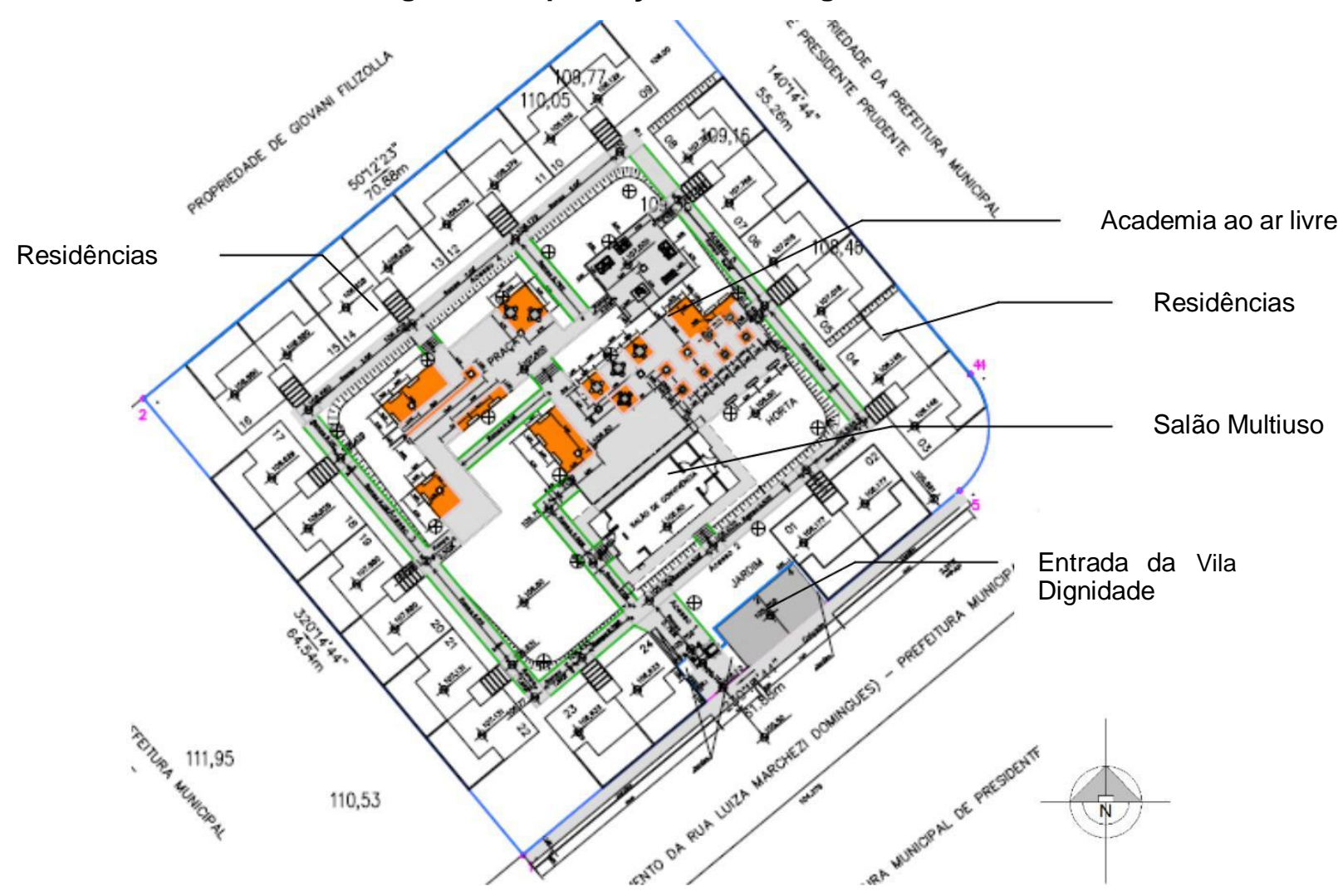

Fonte: CDHU de Presidente Prudente - SP (2015).

O projeto foi elaborado de acordo com as premissas do Desenho Universal, sendo incorporados elementos associado ao conforto, à segurança, além de garantir a acessibilidade. 


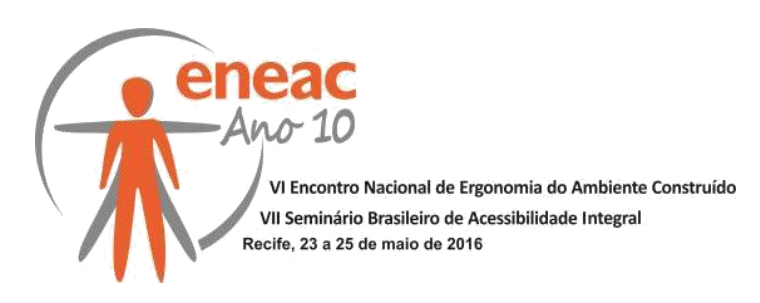

Figura 3 - Dimensões mínimas para a faixa de deslocamento linear

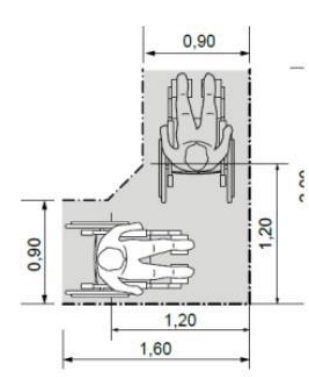

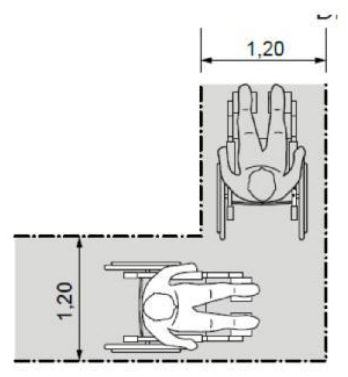

Figura 4 - Dimensionamento referencial e área de manobra
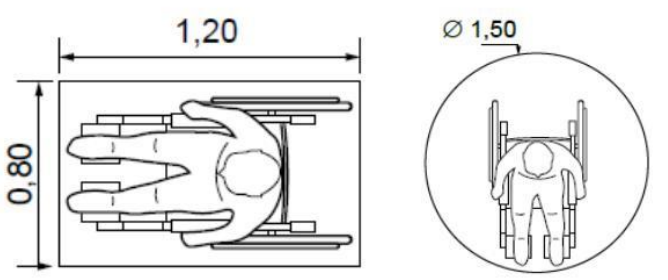

Fonte: ABNT, 2015.

A entrevista estruturada teve por objetivo identificar o nível de satisfação de cada morador em relação à acessibilidade espacial, ao conforto térmico, a facilidade no deslocamento dentro das habitações, e o nível de iluminação. A aplicação dos questionários foi realizada entre os meses de junho e julho de 2015. Foram aplicados 19 questionários, que representou $80 \%$ do total de moradores do condomínio. As questões eram compostas por respostas fechadas (múltipla escolha) que permitiram identificar através de parâmetros quantitativos e qualitativos, o perfil dos usuários e avaliar a qualidade espacial da Vila Dignidade.

Para avaliar a qualidade espacial sob o ponto de vista dos usuários foi utilizado o Método de Análise Multicritério; em particular, o Método da Escala Pontos. Foi adotada a Escala de cinco pontos cujo parâmetro de avaliação variava de ótimo a péssimo. A escala de valores era: valor 1 (péssimo), 2 (ruim), 3 (regular), 4 (bom), e 5 (ótimo). A análise foi realizada utilizando o ranking dos indicadores de nível de importância. Inicialmente, foi calculado o peso médio de cada critério por avaliador. Posteriormente, foram realizados os cálculos dos valores médios dos pesos encontrados pelos indicadores avaliados e definidos os seus rankings (MAGAGNIN; FONTES;SALCEDO, 2014).

\section{$3 \quad$ Analise dos resultados}

Nesta seção são apresentadas as análises dos dados obtidos em relação a análise da acessibilidade espacial na área interna das residências e o nível de satisfação dos usuários sobre esse aspecto na Vila Dignidade.

\subsection{Análise do deslocamento linear e utilização dos ambientes}

A primeira etapa dos estudos consistiu na análise da área livre de circulação de usuários de cadeira de rodas em duas residências tipo. Para esta análise foi utilizada como referência a medida estabelecida pela norma NBR 9050 que define um espaço de 0,90m para esta circulação. De acordo com Pereira (2007) a área de circulação é compreendida pelo espaço mínimo para que o usuário possa chegar até o ambiente, entrar, percorrer e sair do espaço, tendo a possibilidade de aproximar dos equipamentos e mobiliários.

Para isso, foi utilizada a planta humanizada com o layout de duas residências: uma com cama de casal (denominada de residência com mobiliário tipo I) e a outra com cama de solteiro (residência com mobiliário tipo II). A disposição dos mobiliários na planta teve como referência a localização dos móveis encontrados nas casas dos moradores analisados. 


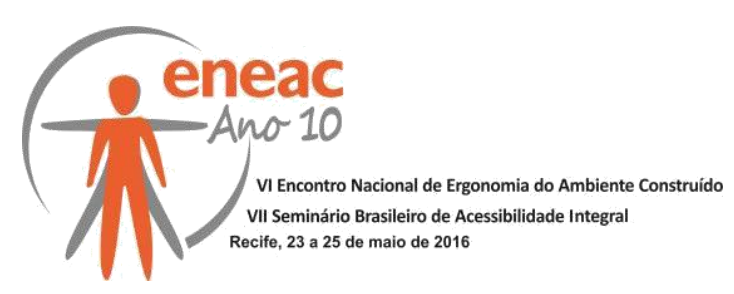

Nestas plantas, os percursos traçados permitem o livre acesso do usuário ao desempenho das funções domésticas essenciais para o cotidiano na habitação; ou seja, deslocar nos ambientes, alcançar os mobiliários, e equipamentos; movimentos indispensáveis no dia a dia de um morador. Estas análises são apresentadas nas Figuras 5 e 6.

\section{Figura 5 - Residência com mobiliário tipo I, sem escala}

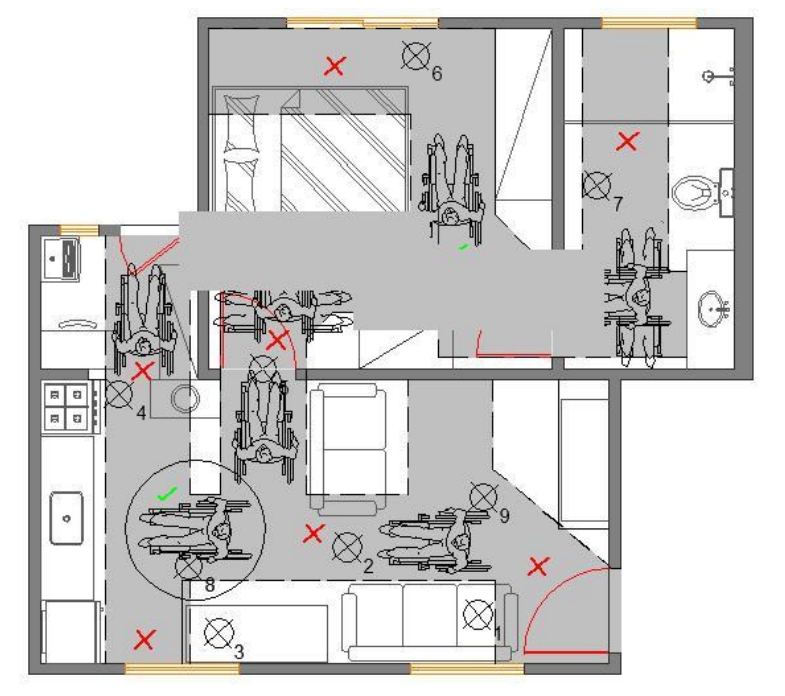
área de rotação da cadeira de rodas

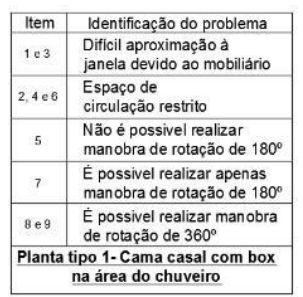

A análise do deslocamento linear na Residência com mobiliário tipo I mostrou que a disposição do mobiliário prejudica o deslocamento do usuário de cadeira de rodas na casa (Figura 5). Na área das portas, a maioria permite a passagem da cadeira de rodas, com exceção para porta que dá acesso a área externa do quintal. A circulação ficou prejudicada nos seguintes locais: na passagem entre a sala para a cozinha, por apresentar largura de 72 $\mathrm{cm}$; o percurso entre a cozinha para a área de serviço apresenta largura de $53 \mathrm{~cm}$, situação que se agrava pela existência do bebedouro e do armário. Já as áreas de aproximação dos mobiliários pode-se observar que a circulação ficou prejudicada entre o trajeto próximo a cama e área de aproximação à porta balcão do quarto, por apresentar largura de $60 \mathrm{~cm}$; e nas áreas de aproximação das janelas da sala e cozinha devido à disposição dos mobiliários.

Sobre a área de giro ou manobra da cadeira de rodas, observou-se certa limitação no deslocamento devido as dimensões dos ambientes e pela disposição dos mobiliários. Os locais onde a área de manobra é restrita a 90ำ ou 180ํㅗ̃o: no percurso entre a sala e o quarto; no banheiro e área de serviço.

Em relação à Residência com mobiliário tipo /l foram observados os mesmo problemas da residência anterior, pois a planta é a mesma. A exceção em relação ao deslocamento linear foi constatada nos ambientes: quarto e banheiro (Figura 6).

$\mathrm{Na}$ área de aproximação dos mobiliários os problemas foram encontrados nos seguintes locais: na área de circulação entre a cama e à porta balcão do quarto, apresenta largura de $80 \mathrm{~cm}$; o mesmo ocorre nas áreas de aproximação das janelas da sala e cozinha, devido à disposição dos mobiliários. 


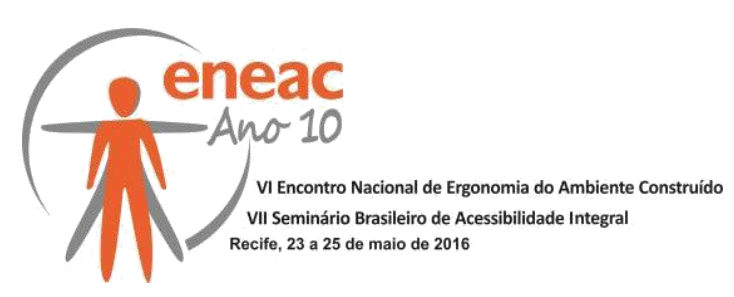

Figura 6 - Residência com mobiliário tipo II, sem escala

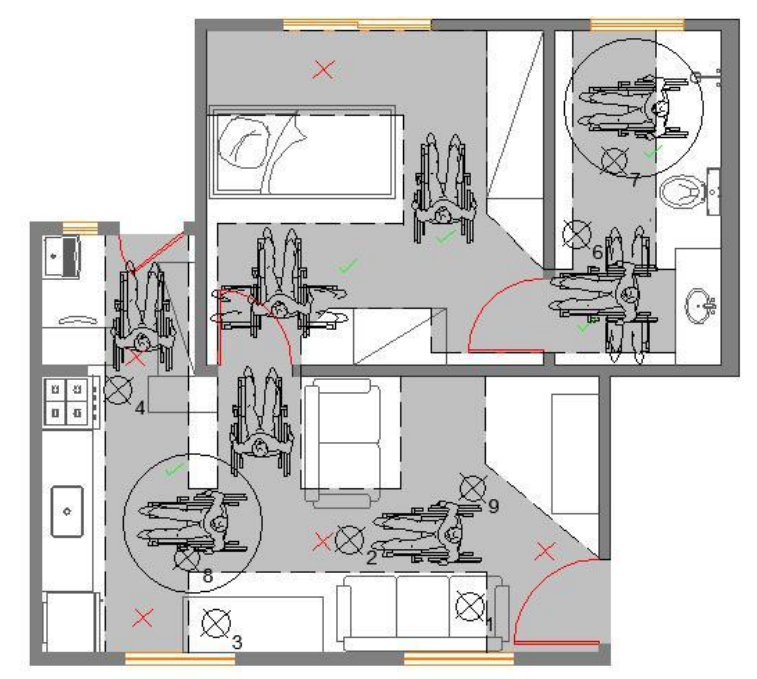

Legenda: área de rotação da cadeira de rodas

A área de giro ou manobra da cadeira de rodas ficou comprometida nos seguintes ambientes: nos pontos de passagem da cozinha para a área de serviço e devido a disposição dos mobiliários há dificuldade no ponto de passagem da porta de entrada para a sala e da sala para a cozinha.

As análises mostram que, embora as residências tenham sido projetadas seguindo os padrões de acessibilidade espacial, a dimensão interna dos ambientes associada a quantidade de mobiliário dos moradores comprometem a sua mobilidade, caso tenham que utilizar uma cadeiras de rodas.

O dimensionamento dos ambientes destinados à cozinha, circulação e sanitários; bem como a disposição das peças sanitárias tornaram estes não acessíveis a qualquer usuário que dependa de um equipamento físico para se locomover nestes espaços. Esta redução na área interna dos ambientes é decorrente da atual política habitacional no Brasil que tem levando em consideração prioritariamente o baixo custo das habitações em detrimento de uma melhoria na qualidade do espaço habitacional.

\subsection{Análise do nível de satisfação dos usuários}

A segunda etapa consistiu na aplicação de questionários aos moradores. A Tabela 1 apresenta o resultado da avaliação do nível de satisfação dos usuários em relação à acessibilidade espacial.

A análise do tema Qualidade da Residência mostrou que ambientes que receberam as piores avaliações foram: a lavanderia, o quintal, a sala e a cozinha, pois são muito pequenos para a realização das atividades diárias. Estes problemas são decorrentes da etapa projetual onde o espaço é pensado para atender minimamente as definições dos códigos de obras locais. 


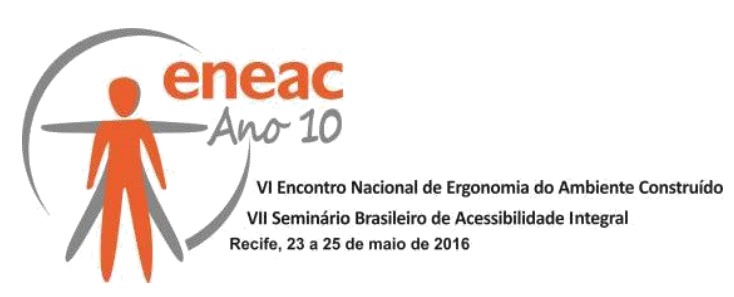

Tabela1 - Síntese da avaliação do nível de satisfação dos moradores

\begin{tabular}{|c|c|c|c|c|}
\hline TEMAS & INDICADORES & PESOS & $\begin{array}{l}\text { RANKING } \\
\text { PARCIAL }\end{array}$ & $\begin{array}{l}\text { RANKING } \\
\text { GERAL }\end{array}$ \\
\hline \multirow{6}{*}{$\begin{array}{l}\text { Qualidade da } \\
\text { Residência }\end{array}$} & I1 - Dimensão da sala & 0,047 & 3 & 22 \\
\hline & 12 - Dimensão do quarto & 0,048 & 4 & 23 \\
\hline & I3 - Dimensão do banheiro & 0,049 & 5 & 24 \\
\hline & 14 - Dimensão da cozinha & 0,047 & 3 & 21 \\
\hline & I5 - Dimensão da lavanderia & 0,044 & 1 & 14 \\
\hline & 16 - Dimensão do quintal & 0,046 & 2 & 19 \\
\hline \multirow{8}{*}{$\begin{array}{l}\text { Características } \\
\text { da Residência }\end{array}$} & 17 - Qualidade do piso - molhado & 0,041 & 2 & 10 \\
\hline & I8 - Quantidade de barras de apoio & 0,042 & 3 & 12 \\
\hline & 19 - Quantidade de janelas & 0,045 & 5 & 17 \\
\hline & I10 - Qualidade da ventilação & 0,044 & 4 & 15 \\
\hline & I11 - Temperatura no inverno & 0,042 & 3 & 11 \\
\hline & I12 - Temperatura no verão & 0,037 & 1 & 5 \\
\hline & I13 - Altura dos interruptores & 0,046 & 6 & 20 \\
\hline & I14 - Altura das tomadas & 0,046 & 6 & 18 \\
\hline \multirow{7}{*}{$\begin{array}{l}\text { Qualidade da } \\
\text { Vila Dignidade }\end{array}$} & I15 - Tamanho da área de lazer & 0,044 & 7 & 16 \\
\hline & $\begin{array}{l}\text { 16- Estado de conservação dos } \\
\text { equipamentos de ginástica }\end{array}$ & 0,025 & 1 & 1 \\
\hline & 117 - Segurança no condomínio & 0,035 & 3 & 4 \\
\hline & I18 - Iluminação do condomínio & 0,040 & 5 & 8 \\
\hline & $\begin{array}{l}\text { I19 - Qualidade da sombra oferecida pela } \\
\text { vegetação do condomínio }\end{array}$ & 0,039 & 4 & 7 \\
\hline & 120 - Altura dos degraus das escadas & 0,034 & 2 & 2 \\
\hline & I21 - Inclinação das rampas & 0,043 & 6 & 13 \\
\hline \multirow{3}{*}{$\begin{array}{l}\text { Qualidade do } \\
\text { Bairro }\end{array}$} & $\begin{array}{l}\text { I22 - Localização do bairro em relação ao } \\
\text { centro da cidade }\end{array}$ & 0,040 & 3 & 9 \\
\hline & $\begin{array}{l}\text { I23 - Distância até o ponto de ônibus } \\
\text { mais próximo }\end{array}$ & 0,038 & 2 & 6 \\
\hline & 124 - Iluminação do bairro & 0,036 & 1 & 3 \\
\hline
\end{tabular}

Em relação ao tema Característica da Residência, as piores avaliações foram referentes aos seguintes problemas: temperatura no verão, qualidade do piso, temperatura no inverno e quantidades de barras de apoio. Estes problemas são decorrentes em sua maioria devido ao clima da cidade. As residências foram projetadas com o sistema Light Steel Frame, porém o fato das casas serem padronizadas significa que não foi levada em consideração a orientação solar, por este motivo algumas residências recebem maior incidência solar do que deveriam, caso fossem projetadas com a insolação correta. O piso cerâmico deveria ser antiderrapante, pois quando molhado prejudica na acessibilidade dos idosos. As barras de apoio estão presentes apenas no vaso sanitário e chuveiro, o que significa que há falta nos demais equipamentos e ambientes como área de serviço e cozinha. 


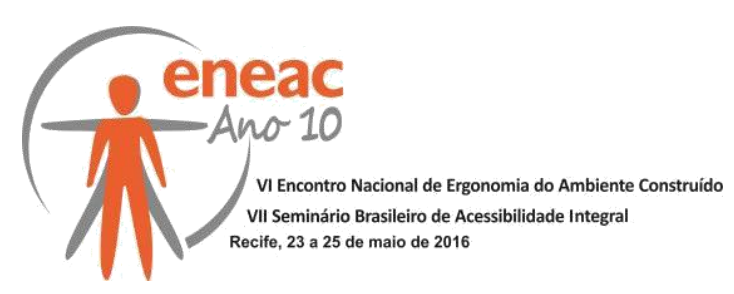

A análise do tema Qualidade da Vila Dignidade revelou que os piores ambientes foram: estado de conservação dos equipamentos de ginástica; altura dos degraus das escadas e segurança no condomínio. Apesar da área de lazer e ginástica, os equipamentos de ginástica não são muito utilizados pelos moradores em sua maioria, o que fez com que os resultados dos questionários pontuassem de maneira negativa. Pela vila dignidade ter sido implantada em um terreno em aclive, a presença de degraus irregulares dificulta 0 deslocamento dos idosos nas áreas livres de lazer. Como a localização do Condomínio é afastada do centro da cidade, e por não haver um entorno edificado, gera insegurança aos moradores que precisam realizar atividades externas.

Na análise do tema Qualidade do Bairro os indicadores que receberam as piores avaliações foram: iluminação do bairro, distância do ponto de ônibus e distância do condomínio até o centro da cidade. O Condomínio se encontra afastado do centro da cidade e o bairro pouco habitado e com iluminação deficiente prejudica a circulação dos idoso no entorno do condomínio.

Analisando todos os Indicadores através do ranking geral, o diagnóstico apontou que os principais problemas da Vila Dignidade referem-se: estado de conservação dos equipamentos de ginástica (1 $1^{\underline{a}}$ posição), altura dos degraus das escadas (2a posição), lluminação do bairro ( $3^{\underline{a}}$ posição), segurança no condomínio (4⿳亠丷a posição), e temperatura da residência no verão ( $5^{\underline{a}}$ posição).

A partir desses resultados ressaltam-se dificuldades e insatisfação por parte dos moradores em relação às residências e ao conjunto como um todo. O fato do condomínio possuir casas padronizadas dificulta o aproveitamento individual da luz solar e sua localização interfere diretamente na segurança e qualidade do bairro. Isso significa que é necessário rever alguns conceitos e projetos a fim de promover melhorias e melhor qualidade de acessibilidade e conforto para os moradores.

\section{Considerações Finais}

Apesar das residências terem sido projetadas de acordo com as normas de acessibilidade e incorporando as necessidades físicas e psicológicas do idoso, observou-se que há a necessidade de se repensar neste projeto.

Os principais problemas identificados quanto à acessibilidade foram: tamanho dos cômodos considerados insuficientes e não acessíveis em relação à disposição dos mobiliários e largura insuficiente nos pontos de passagem de um cômodo ao outro devido à disposição dos mobiliários.

Em relação aos demais critérios analisados ressaltam-se a reclamação por parte dos moradores com relação à iluminação noturna no condomínio, a falta de sombreamento no condomínio e a má localização do condomínio em relação ao centro da cidade, isso é decorrente da localização do condomínio.

Espera-se que pesquisas como esta possa servir de contribuição para a compreensão do universo e das necessidades habitacionais do idoso, além de servir de subsídio para definição de parâmetros para a elaboração para a elaboração de novos projetos e programas relacionados à habitação para este público. 


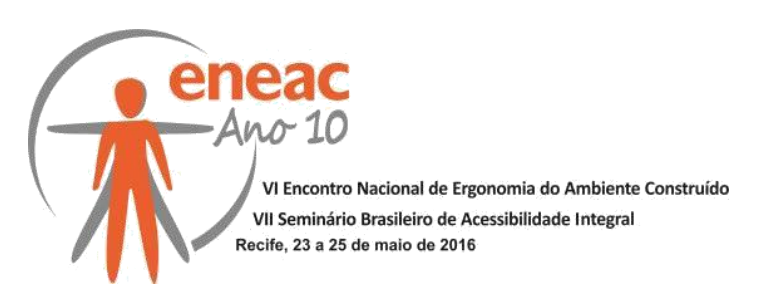

\section{REFERÊNCIAS}

ASSOCIAÇÃO BRASILEIRA DE NORMAS TÉCNICAS. NBR 9050. Acessibilidade de pessoas portadoras de deficiências a edificações, espaço, mobiliário e equipamentos urbanos. Rio de Janeiro, 2004.

ASSOCIAÇÃO BRASILEIRA DE NORMAS TÉCNICAS. NBR 9050. Acessibilidade de pessoas portadoras de deficiências a edificações, espaço, mobiliário e equipamentos urbanos. Rio de Janeiro, 2015.

BESTETTI, M. L. T. Habitação para idosos. 0 trabalho do arquiteto, arquitetura e cidade. Tese (Doutorado). FAU/USP. 2006.

BINS ELY, V. H. M.. DORNELES, V. G. Acessibilidade Espacial do Idoso no Espaço Livre Urbano. In: ABERGO, 2006, Curitiba. 8p.

BRASIL. Déficit habitacional no Brasil 2008. Ministério das Cidades. Secretaria Nacional de Habitação. - Brasília, Ministério das Cidades, 2011.140 p.

HAZIN, M. M. V. Os Espaços Residenciais na Percepção dos Idosos Ativos. Dissertação (Mestrado em Design). Universidade Federal de Pernambuco. Recife. 2012.

IBGE- Instituto Brasileiro de Geografia e Estatística. Censo Demográfico 2010. Disponível em: <www.ibge.gov.br> Acesso em: 20 jun. 2015.

MAGAGNIN, R. C.; FONTES, M. S. G. de C.; SALCEDO, R. F. B. Spatial quality evaluation of pedestrian streets. Journal of Civil Engineering and Architecture (Online), v. 8, 1574-1584. 2014.

MILANI, D.A. O Quarto e o Banheiro do Idoso: Estudo, análise e recomendações para o espaço do usuário residente em instituição de longa permanência. Dissertação (Mestrado em Arquitetura e Urbanismo). Universidade de São Paulo. São Paulo, SP. 2014

MONTEIRO, L.C.A. Políticas públicas habitacionais para idosos: um estudo sobre os condomínios exclusivos. Tese (Doutorado). Universidade Federal de São Carlos. 2012.

PEREIRA, G. M. Acessibilidade Espacial na Habitação Popular: Um Instrumento para Avaliação de Projetos. Dissertação (Mestrado em Arquitetura e Urbanismo). Programa de Pós-Graduação. Florianópolis, SC. 2007.

PISTORI, C. R. A. T.; FERRÃO, A. M. de A. Recomendações para o projeto de ambientes adequados ao uso da população idosa. 2004. Anais ... Congresso ENTAC. Disponível em: http://www.argollo.org/artigos_texto/Entac2004_cassia.pdf. Acesso em 3 ago. 2015.

PRADO, B.B.; LELIS, V. F.; AMARO, E. K. P.; MAGAGNIN, R. C.. Spatial accessibility for elderly in a multi residential condominium in Brazil. In: 14th International Conference on Mobility and Transport for Elderly and Disabled Persons - TRANSED, 2015, Lisboa. 2015. p. A329-A342.

SÂMIA, C.O. F. Cozinha funcional: análise do espaço e do usuário idoso. Dissertação (Mestrado em Design e Arquitetura). Universidade de São Paulo. São Paulo, SP. 2008.

SALCEDO, R. F. B.; MAGAGNIN, R. C.; PEREIRA, T. C. (2012). Qualidade dos espaços construídos em habitações de interesse social para idosos. Estudo de Caso: Vila dos Idosos, Ambiência do centro histórico de São Paulo. In: V Congresso Luso Brasileiro para o Planejamento Urbano, Regional, Integrado e Sustentável - PLURIS 2012: Reabilitar o Urbano, v. 1, 1-12. Brasilia: Universidade de Brasília. 


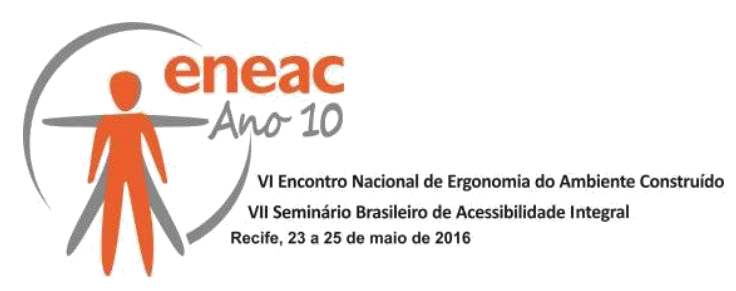

SCHUSSEL, Z. das G.L. (2012, dezembro). Os idosos e a habitação. Revista Kairós Gerontologia,15(8), pp.53-66. Online ISSN 2176-901X. Print ISSN 1516-2567. São Paulo (SP), Brasil: FACHS/NEPE/PEPGG/PUC-SP. 